\title{
Amiodarone Toxicity: A Case Report
}

Amiodarone is one of the commonly used drug in arrhythmias. It is first line of treatment for ventricular tachycardia particularly in treatment of supraventicular tachycardia like atrial fibrillation. Amiodarone has a wide range of adverse effects ranging from endocrine to cardiac system. A case of raised thyroid stimulating Hormone (TSH) with amiodarone was reported in our Adverse drug monitoring centre (AMC), in which several other adverse events such as raised raised billirubin and hyponatremia were present. Patient was treated with thyroxine while amiodarone along with atorvastatin and metoprolol were withdrawn. We present a case who developed subclinical hypothyroidism, electrolyte imbalance and liver dysfunction with amiodarone therapy.

KEYWORDS: Amiodarone, Percutaneous transluminal coronary angioplasty (PTCA), Toxicity

\section{INTRODUCTION}

Arrhythmias are disturbance of either cardiac rhythm generation or conduction. Amiodarone is frequently used drug in arrhythmias. It is first line of treatment for ventricular tachycardia, ${ }^{1}$ particularly effective in supraventicular tachycardia like atrial fibrillation. Adverse effect of amiodarone includes cardiac and extra cardiac effects. Hormonal disturbance such as hyper/hypo thyroids can manifest due to high iodine content in the drug. Abnormal liver function, photodermatitis, corneal deposit, bradycardia, heart block with pre-existing AV node pathology, vasodilation can be seen on this drug administration. ${ }^{2}$ There are some rare adverse effects of amiodarone such as Pulmonary fibrosis and syndrome of inappropriate diuretic hormone (SIADH). We report a patient who developed multiple complications after amiodarone therapy which included hypothyroidism, hyponatremia, increased bilirubin. Extent of relationship between a drug and a suspected reaction is established by Causality assessment. It is often difficult to decide if an adverse clinical event is anadverse drug reaction (ADR) or due to deterioration in the primary clinical condition.

Furthermore, if it is an ADR, then which drug caused it, as many patients are on multiple new medications when ill, especially if hospitalized. Algorithms being structured systems specifically designed for establishing causal relationship of drug to an ADR, make more objective decision on causality assessment. A number of algorithms or decision aids have been published for casualty assessment including the Jones 'algorithm, the Naranjo algorithm, the Yale algorithm, the Kerch algorithm, the Begaud algorithm, the Adverse Drug Reactions Advisory Committee (ADRAC), the WHO UMC, and a newer quantitative approach Algorithm. ${ }^{3}$ For present study, we have established causality relationship of ADRs with drugs using Naranjo scale.

\section{CASE REPORT}

A spontaneously reported case of 52 year old male presented with abdominal discomfort, palpitation, tiredness and weakness while undergoing treatment with amiodarone, atorvastatin, metoprolol, aspirin and prasugrel.

Patient had underwent Percutaneous transluminal coronary angioplasty (PTCA) in Left anterior descending artery (LAD) one and a half month back. His hospital stay was uneventful. He was discharged and was prescribed atorvastatin, amlodipine, aspirin and prasugrel.

Two days after discharge, patient reported to hospital with complaint of diffuse chest pain which was dull and non-radiating, associated with palpitation along with dyspnea (grade NHYA 2). He was diagnosed with atrial fibrillation and was given amiodarone intravenous(i.v.) infusion to control the arrhythmia. Patient was prescribed oral amiodarone (200 mg) along with metoprolol, aspirin and prasugrel on discharge from hospital. Dose of amiodarone was reduced to $100 \mathrm{mg}$ on follow up after 1 month.

One and a half month later, patient presented with 
abdominal discomfort, palpitation, tiredness and weakness. Patients thyroid stimulating hormone (TSH) was raised (13.72 $\mathrm{uIU} / \mathrm{ml}$; normal range: $0.35^{-}$ $5.5 \mathrm{uIU} / \mathrm{ml})$, bilirubin was raised $(2.8 \mathrm{mg} / \mathrm{dl}$; normal range: o-1 mg/dl) and patient had hyponatremia (125 $\mathrm{mmol} / \mathrm{L}$; normal range: $135-145 \mathrm{mmol} / \mathrm{L}$ ) and hypokalemia ( $3.4 \mathrm{mmol} / \mathrm{L}$; normal range: 3.6-5.0 $\mathrm{mmol} / \mathrm{L})$. It was accompanied by proteinuria (350mg/24 hr; normal range: $40-150 \mathrm{mg} / 24$ hours). He was admitted to hospital after 2 days where his sodium $(\mathrm{Na}+)$ level further decreased to $109 \mathrm{mmol} / \mathrm{L}$ and his anti-thyroid peroxidase (anti TPO) antibodies came out to be $250 \mathrm{IU} / \mathrm{ml}$ (normal range: $60 \mathrm{IU} / \mathrm{ml}$ ). He was treated will oral and i.v sodium and iv potassium, thyroxine $(50 \mathrm{mcg})$ while amiodarone, atorvastatin and metoprolol were withdrawn. Patient was treated with aspirin, prasugrel, and simvastatin. Patient was regularly followed up for sodium and TSH level. There was a gradual decrease in TSH level and TSH was within normal limit $(3.5 \mathrm{uIU} / \mathrm{ml})$ after 2 months. The $\mathrm{Na}+$ levels were still low $(3.57 \mathrm{mmol} / \mathrm{ml})$, while the potassium levels came back to normal.

The patient was non-smoker. He had history of hypertension and was treated with telmisartan for 10 years. He was diagnosed with obstructive sleep apnea six months back and was on nocturnal CPAP since then. Patient had a single episode of increased TSH one year (7.9ouIU/ml). His Anti TPO level was 70.9 $\mathrm{IU} / \mathrm{ml}$. However, patient was always euthyroid, so no medication was started. During the investigation performed before PTCA patient had TSH within normal limit.

\section{DISCUSSION}

Amiodarone is a structural analogue of thyroid hormone. Being a highly lipophilic drug, it gets accumulated in many tissues and is slowly eliminated from the body. This may be reason for its prolonged adverse effects with late recovery. ${ }^{1}$ It contain $37 \%$ iodine in its structure i.e. $200 \mathrm{mg}$ iodine provides 75 $\mathrm{mg}$ of iodine to the patient. This may lead to either hypo or hyperthyroidism as seen in case discussed above. This is seen especially in patients with underlying hashimoto's disease or grave disease. ${ }^{4}$ The above case had one recorded episode of raised TSH and Anti TPO antibodies and was on amiodarone therapy, which may have predisposed him to development of sub clinical hypothyroidism as was evident with the increase in TSH levels and normal $\mathrm{T}_{3}, \mathrm{~T}_{4}$ levels.
Hyponatremia is a rare complication with amiodarone. ${ }^{5}$ Causality assessment of hyponatremia was probable for amiadarone, atorvastatin and metoprolol according to naranjo scale. In above case along with hyponatremia, patient had other electrolyte imbalance such as hypokalemia. Following Naranjo scale, causality assessment of hypokalemia is probable for amiodarone, atorvastatin and metoprolol. Proteinuria seen in this case can be attributed to hypertension affecting kidney or the drugs given which was further investigated. Causal relationship of proteinuria was possible for amiodarone, atorvastatin and metoprolol according to naranjo causality assessment scale.

Pulmonary fibrosisis the main concern in amiodarone toxicity as it may prove to be fatal. ${ }^{1}$ However, in our case no pulmonary changes were reported. Any hepatotoxic injury is indicated by raised liver enzyme such as Alkaline phosphatase (ALP), Aspartate transaminase (AST) etc. However, we only observed raised bilirubin in patient with normal liver enzyme. Increase in bilirubin may be due to amiodarone or atorvastatin.

\section{CONCLUSION}

Amiodarone, although a very effective tool in arrhythmia, should be used judiciously and patients should be monitored for thyroid, liver and electrolyte imbalance to detect any untoward event early during the therapy.

Abbreviations: TSH-thyroid stimulating Hormone, SIADH-syndrome of inappropriate diuretic hormone, PTCA-Percutaneous transluminal coronary angioplasty, LAD- Left anterior descending artery, TPO-thyroid peroxidase.

\section{REFERENCES}

1. Burton LL, Dandan RH, knollmann BC. editors. Goodman's and gillman's the pharmacological basis of therapeutics.13 ${ }^{\text {th }}$ ed. New York: Mcgraw hill. 2018.

2. Srinivasan R, Ramya G. Adverse drug reactioncausality assessment. IJRPC. 2011;1(3):606-13.

3. Katzung BG, Trevor AJ. Editors. Basic and clinical pharmacology. $14^{\text {th }}$ ed. New Delhi. Mcgraw Hill; 2018.

4. Narayana SK, Woods DR and Boos CJ.Management of amiodarone-related thyroid problems. Ther Adv Endocrinol Metab.2011;2(3):115-26. 
5. Pham L, Shaer AJ, Marnejon T. Hyponatremia - A Rare but Serious Complication of Amiodarone: A Case Report and Review of the Literature Case Rep Nephrol Urol. 2013;3:46-50.

Source of support: Nil, Conflict of interest: None declared

Cite this article as:

Lal H, Singh J, Kumar V, Bhajni E, Sehgal VK. Amiodarone Toxicity: A Case

Report. Int Healthc Res J. 2018;2(10):250-252. doi: 10.26440/ihrj.v2i1o.193

\section{AUTHOR AFFILIATIONS:}

1. Junior Resident, Department of Pharmacology, GMC Patiala

2. Senior Resident, Department of Pharmacology, GMC Patiala

3. Chief Medical Officer, Railway Hospital , Patiala

4. Junior Resident, Department of Pharmacology, GMC Patiala

5. Professor, Department of Pharmacology, GMC Patiala

*Corresponding Author:

Dr. Jatinder Singh

Senior Resident

Department of Pharmacology GMC Patiala
For article enquiry/author contact details, e-mail at: editor.ihri@gmail.com,editor@ihrjournal.com 